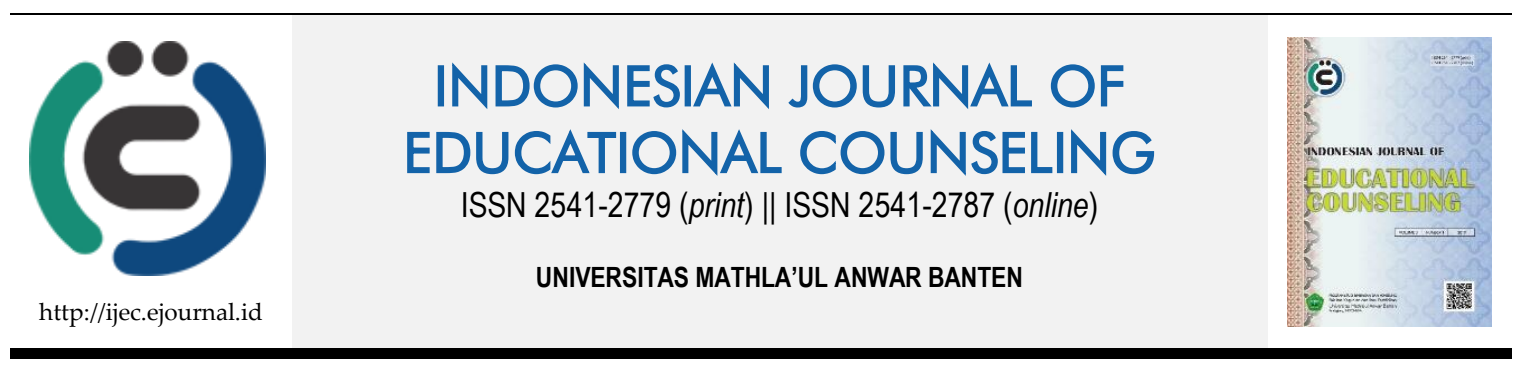

Research Based Article

\title{
Pola Asuh Otoriter tidak Berhubungan Signifikan dengan Konsep Diri Siswa SMA
}

\author{
Santa Yopita Kemit ${ }^{1}$, Lobby Loekmono ${ }^{2}$, Setyorini ${ }^{3}$ \\ 1, 2, 3 Universitas Kristen Satya Wacana, Salatiga
}

\begin{tabular}{ll}
\hline Article History & ABSTRACT \\
\hline $\begin{array}{l}\text { Received: 27.08.2018 } \\
\text { Received in revised form: }\end{array}$ & This study aims to determine the significant relationship between authoritarian \\
20.12.2018 & parenting and the self-concept of SMA Kristen 1 Salatiga especially students ini \\
Accepted: 04.01.2019 & class XII. The measuring instrument used in this study is Scale of Parenting \\
Available online: 24.01 .2019 & Style compiled by Gafoor and Kurukkan (2014) referring to the theory of \\
& Baumrind (1991) and Self-Description Questionnaire II (SDQ-II) compiled by \\
& Herbert W. Marsh (1990). The data analysis technique used in this study is \\
& Pearson Product Moment Correlation by using SPSS for Windows 20. From the \\
& results of the data analysis, the results show that there is no significant \\
& relationship between the authoritarian parenting style with the self-concept of \\
& Christian XII grade students 1 Salatiga with the correlation of rxy = 0.110 with \\
& P=0.388> 0.05. That is, the increase or decrease in the score of the authoritarian \\
parenting variable and the self-concept variable score cannot be determined. & \\
& Keywords: Authoritarian Parenting, Self-concept.
\end{tabular}

DOI: 10.30653/001.201931.49

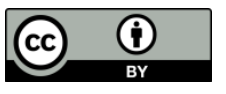

This is an open access article distributed under the terms of the Creative Commons Attribution 4.0 International License, which permits unrestricted use, distribution, and reproduction in any medium, provided the original work is properly cited. (c) 2019 Santa Yopita Kemit, Lobby Loekmono, Setyorini.

\section{PENDAHULUAN}

Konsep diri diartikan sebagai evaluasi atau penilaian individu mengenai diri sendiri oleh individu yang bersangkutan (Chaplin, 1989). Konsep diri merupakan gambaran diri sendiri yang terdiri atas pengetahuan diri, harapan dan penilaian tentang diri sendiri yang terdiri dari terdiri tiga aspek: akademik, non-akademik, dan umum (Marsh, 1990).

Konsep diri akademik dibagi menjadi konsep diri dalam mata pelajaran yaitu matematika, bahasa dan mata pelajaran sekolah secara umum. Konsep diri non-akademik mencakup penampilan fisik, kejujuran-kepercayaa, kemampuan fisik, stabilitas emosional, hubungan dengan orang tua, hubungan dengan teman sejenis, hubungan dengan teman lawan jenis. Adapun konsep diri umum (general self) merupakan gambaran umum diri sendiri. 
Salah satu faktor yang turut membentuk konsep diri anak selain lingkungan adalah pola asuh orang tua, sehingga konsep diri bukanlah faktor bawaan. Sikap orang tua yang terbaca oleh anak akan mengembangkan konsep diri dan pemikiran anak (Vinayastri, 2015).

Pola asuh menggunakan dua dimensi, yaitu tuntutan orang tua (kontrol, pengawasan, permintaan dewasa) dan responsif (kehangatan, penerimaan keterlibatan) yang keduanya berpola mengikuti empat pola asuh orang tua yaitu authoritative (tuntutan tinggi dan responsif tinggi), authoritarian (tuntutan tinggi dan responsif rendah), permissive (tuntutan rendah dan responsif tinggi) dan neglecting (tuntutan rendah dan responsif rendah) (Baumrind, 1991). Pola asuh yang akan dibahas dalam penelitian ini adalah pola asuh tipe authoritarian (otoriter). Orang tua authoritarian (otoriter) memiliki kendali yang kuat dan sangat membatasi. Pola asuh orang tua yang authoritarian (otoriter) memiliki dampak kepada anak karena orang tua menghendaki anak untuk menaati aturan tanpa memberi penjelasan. Akibatnya anak yang tumbuh dalam pola asuh seperti ini biasanya menerima sikap tidak adil dari orang tua. Orang tua dengan pola asuh authoritarian (otoriter) menghasilkan konsep diri anak yang rendah dimana anak cenderung merasa gagal dalam hidup mereka karena selalu membuat masalah dan merasa tidak puas dalam segala hal tentang diri mereka sendiri atau hal-hal lain yang terjadi di sekitar mereka (Rahman, Shahrin, \& Kamaruzaman, 2017).

Pra penelitian yang dilakukan kepada 30 responden siswa kelas XII IPS-3 SMA Kristen 1 Salatiga diperoleh hasil $53.33 \%$ siswa memiliki pola asuh orang tua yang authoritarian (otoriter). Hasil pra penelitian mendapati ada hubungan yang signifikan ( $\mathrm{r}=$ 0,929 ) antara pola asuh orang tua yang otoriter (authoritarian) dengan konsep diri siswa kelas XII-IPS 3 SMA Kristen 1 Salatiga. Berbeda dengan hasil penelitian Ganda (2015) yang menghasilkan tidak ada hubungan yang signifikan antara pola asuh orang tua authoritarian dengan konsep diri siswa SMA Kelas XI SMA Kristen 1 Salatiga dengan koefisien korelasi $\mathrm{r}_{\mathrm{xy}} 0,462$ dan $\mathrm{p}=0,784>0,05$. Untuk itu perlu melakukan penelitian dengan responden yang mencukupi untuk jenis penelitian survei yang membutuhkan responden yang besar untuk membuat sebuah kesimpulan.

\section{Konsep Diri}

Marsh (1990) mendefinisikan konsep diri sebagai gambaran diri sendiri yang terdiri atas pengetahuan, harapan, dan penilaian tentang diri sendiri. Konsep diri terdiri dari 11 aspek yang dikelompokkan menjadi tiga konsep diri akademik, tujuh konsep diri non akademik dan satu konsep diri umum (Marsh, 1990).

Konsep diri akademik adalah evaluasi diri yang terbentuk melalui pengalaman yang disertai interpretasi terhadap lingkungan sekolah (Marsh \& Craven, 1996). Konsep diri akademik dibagi menjadi konsep diri dalam mata pelajaran tertentu (matematika dan bahasa) dan sikap umum di sekolah. Mata pelajaran matematika (math) merupakan minat, kemampuan dan ketertarikan siswa terhadap mata pelajaran matematika di sekolah. Mata pelajaran Bahasa (verbal) merupakan penguasaan, minat terhadap pelajaran bahasa, membaca dan bertutur kata dengan orang lain. Sekolah secara umum (general school) merupakan sikap, perilaku dan penyesuaian diri terhadap guru, teman, pelajaran dan lingkungan sekolah itu sendiri. 
Konsep diri non-akademik mencakup tiga bidang: konsep diri sosial yang berhubungan dengan teman sebaya dan orang lain yang signifikan (termasuk hubungan dengan orang tua), konsep diri emosional, dan konsep diri fisik yang terbagi menjadi kemampuan dan penampilan fisik.

Pertama, pada bidang sosial, konsep diri diawali oleh konsep kejujuran-kepercayaan (Honesty-Trustworthiness), yaitu kejujuran dan kepercayaan siswa terhadap orang lain dan juga terhadap dirinya sendiri dalam segala hal yang dilakukan. Konsep diri juga berhubungan dengan bagaimana hubungan siswa terhadap teman sekolah maupun teman di luar sekolah yang berjenis kelamin sama, apakah mudah bergaul dan apakah mempunyai hubungan yang baik atau tidak dengan teman berjenis kelamin sama. Kemudian, hubungan siswa dengan teman sekolah maupun teman di luar sekolah yang berjenis kelamin berbeda, apakah siswa tersebut mudah bergaul, apakah mempunyai hubungan yang baik atau tidak dengan teman lawan jenis. Terakhir, hubungan antara anak dengan orang tuanya (Parent Relations) terutama dalam hal berkomunikasi.

Kedua, konsep diri emosional berhubungan dengan stabilitas emosional (emotional stability), yaitu kesejahteraan emosional siswa untuk mengenal, mengendalikan dan menunjukkan emosinya dalam segala situasi dan kondisi di sekelilingnya. Ketiga, Konsep diri berhubungan dengan kemampuan dan penampilan fisik. Kemampuan fisik berkaitan dengan kemampuan siswa melalukan aktivitas fisik, seperti olahraga dan menari. Adapun penampilan fisik (Physical Appearance) merupakan penampilan fisik diri siswa, kekurangan dan kelebihan dari penampilan fisik yang dimiliki oleh siswa, yang dinilai oleh siswa itu sendiri.

Kelompok pembagian ketiga adalah konsep diri secara umum (general self). Konsep diri secara umum merupakan gambaran umum diri siswa itu sendiri, kepercayaan terhadap dirinya sendiri, kepuasan terhadap dirinya sendiri dan kekurangan serta kelebihan yang dimiliki oleh diri sendiri.

\section{Pola Asuh Orang Tua (Parenting)}

Konseptualisasi pola asuh sebagai metode untuk mengkategorikan dan mengukur nilai dan bentuk hubungan antara orang tua dan anak dimulai dengan penelitian Diana Baumrind (1966). Pola asuh menggunakan dua variabel (Baumrind, 1991). Variabel pertama yaitu tuntutan (demandingness) orang tua juga disebut sebagai kontrol perilaku, mengacu pada orang tua yang membuat anak menjadi terintegrasi oleh tuntutan kedewasaan, pengawasan, upaya disiplin dan kesediaan untuk mengahadapi anak yang tidak taat. Variabel kedua yaitu responsif (responsiveness) juga disebut sebagai daya tanggap, kehangatan, dukungan orang tua dan penerimaan, mengacu pada orang tua dengan sengaja mendorong individualitas, penggaturan diri dan penegasan diri dengan menyesuaikan diri, mendukung dan menyetujui kebutuhan serta permintaan khusus anak.

Baumrind (1991) menggunakan kedua variabel di atas untuk merumuskan keempat pola asuh orang tua yaitu authoritative (tinggi pada tuntutan dan tinggi responsif), authoritarian (tinggi pada tuntutan dan rendah pada responsif), indulgent (rendah pada tuntutan dan responsif tinggi) dan neglecting (rendah pada tuntutan dan rendah responsif). Bagaimana dimensi-dimensi ini bergabung menghasilkan gaya-gaya 
pengasuhan yang authoritative, authoritarian, indulgent, neglecting diperlihatkan dalam Tabel 1.

Tabel 1. Rumusan Empat Pola Asuh Orang Tua

\begin{tabular}{|c|c|c|}
\hline \multicolumn{2}{|r|}{ Tuntutan Tinggi } & Tuntutan Rendah \\
\hline \multirow{13}{*}{ 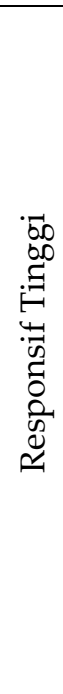 } & Authoritative (otoritatif) & Indulgent \\
\hline & 1) Kontrol yang kuat dan konsisten & 1) Sering berkespresi kehangatan \\
\hline & 2) Memantau dan memberikan & dan kasih sayang \\
\hline & $\begin{array}{l}\text { standar yang jelas untuk perilaku } \\
\text { anak-anak mereka }\end{array}$ & $\begin{array}{l}\text { 2) Penegakan hukum aturan dan } \\
\text { otoritas. }\end{array}$ \\
\hline & 3) Mengutamakan kebutuhan dan & 3) Penerimaan tinggi \\
\hline & kemampuan anak & 4) Mengambil peran sebagai teman \\
\hline & 4) Menyiratkan tuntutan kedewasaan & daripada orang tua \\
\hline & usia yang tepat. & 5) Mengijinkan anak untuk \\
\hline & 5) Mendorong anak untuk mandiri & membuat keputusan sendiri. \\
\hline & 6) Penuh perhatian & 6)Hukuman minimum \\
\hline & 7) Memaafkan & \\
\hline & 8) Mendorong otonomi & \\
\hline & 9) Menawarkan iklim demokratis & \\
\hline \multirow{10}{*}{ 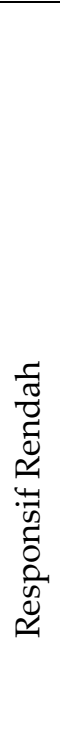 } & Authoritarian (otoriter) & Negligent \\
\hline & 1) Tegas dalam praktik kontrol & 1) Perilaku lalai \\
\hline & 2) Mengharapkan ketaatan yang ketat & 2) Mengabaikan anak \\
\hline & $\begin{array}{l}\text { dan tak perlu dipertanyakan } \\
\text { kepada otoritas orang tua }\end{array}$ & 3)Sedikit interaksi dengan anak \\
\hline & $\begin{array}{l}\text { 3) Belum siap menerima } \\
\text { individualitas anak }\end{array}$ & \\
\hline & 4) Ketidaktaatan ditangani oleh & \\
\hline & $\begin{array}{l}\text { disiplin yang kuat dan bersifat } \\
\text { menghukum. }\end{array}$ & \\
\hline & $\begin{array}{l}\text { 5) Relatif mengabaikan kebutuhan } \\
\text { anak }\end{array}$ & \\
\hline & $\begin{array}{l}\text { 6) Sedikit komunikasi antara orang } \\
\text { tua dan anak. }\end{array}$ & \\
\hline & 7) Perilaku yang sangat direktif & \\
\hline
\end{tabular}

Baumrind (Gafoor \& Kurukkan, 2014)

Orang tua yang authoritarian sering mencoba untuk membentuk, mengendalikan, dan mengevaluasi perilaku anak berdasarkan standar yang mutlak. Orang tua memiliki tuntutan kedewasaan yang tinggi kepada anak. Orang tua bersifat menghukum yang menuntut anak untuk mengikuti perintah orang tua dan menghormati pekerjaan dan usaha orang tua. Orang tua yang authoritarian menetapkan batas-batas yang tegas dan tidak memberi peluang yang besar kepada anak-anak untuk berbicara (bermusyawarah). Orang tua menilai kepatuhan sebagai kebaikan dan mendukung hukuman. Orang tua percaya bahwa anak harus menerima apa yang sudah ditetapkan oleh orang tua karena itu merupakan hal yang benar. 
Orang tua yang authoritative mengakui hak orang tua dan anak, orang tua berusaha untuk membimbing kegiatan anak dengan cara yang rasional dan berorientasi pada masalah. Mendorong anak-anak agar mandiri tetapi masih ada batasan. Orang tua menggunakan kontrol yang kuat pada titik-titik perbedaan orang tua-anak, tetapi tidak membatasi anak dengan pembatasan. Orang tua mendorong dan menerima pendapat anak, berbagi dengan anak alasan di balik kebijakan orang tua dan mengumpulkan keberatan anak ketika anak menolak untuk menyesuaikan diri. Musyawarah verbal yang ekstensif dimungkinkan, dan orang tua memperlihatkan kehangatan serta kasih sayang kepada anak.

Pola asuh neglecting di mana orang tua sangat tidak terlibat dalam kehidupan anak; orang tua tidak memonitor perilaku anaknya ataupun mendukung ketertarikan mereka, kerena orang tua sibuk dengan masalahnya sendiri dan cenderung mengabaikan tanggung jawab sebagai orang tua. Anak-anak memiliki keinginan yang kuat agar orang tua mereka peduli terhadap mereka; anak-anak yang orang tuanya berpola neglecting mengembangkan suatu perasaan bahwa aspek-aspek lain kehidupan orang tua lebih penting dari pada anak mereka. Pola asuh yang neglecting dapat mengakibatkan anak out of control (tidak terkendali) yang berarti anak bersikap tidak menaati aturan/norma yang berlaku, sering melanggar norma-norma dan ketentuan yang ada dalam keluarga dan lingkungan masyarakat.

Pola asuh indulgent dimana orang tua sangat terlibat dalam kehidupan anak-anak mereka tetapi menetapkan sedikit batas atau kendali terhadap mereka. Pengasuhan yang indulgent diasosiasikan dengan ketidakmampuan sosial anak, khususnya kurangnya kendali diri. Orang tua seperti ini memanjakan dan membiarkan anak-anak melakukan apa saja yang dinginkan, dan akibatnya adalah anak-anak tidak pernah belajar mengendalikan perilaku sendiri dan selalu mengharapkan kemauan mereka dituruti. Beberapa orang tua dengan sengaja mengasuh anak-anak mereka dengan pola asuh indulgent ini karena mereka yakin kombinasi keterlibatan yang hangat dengan sedikit kekangan akan menghasilkan seorang anak yang kreatif, percaya diri. Anak-anak yang orang tuanya indulgent jarang belajar menaruh hormat pada orang lain dan mengalami kesulitan mengendalikan perilaku mereka.

\section{METODE}

Jenis penelitian yang digunakan adalah penelitian korelasional. Penelitian korelasional adalah penelitian yang menggunakan metode pertautan atau berusaha menghubung-hubungkan antara satu variabel dengan variabel lain untuk menciptakan bentuk dan wujud baru yang berbeda dengan sebelumnya (Sugiyono, 2015). Penelitian korelasional dalam penelitian ini bertujuan untuk mengetahui hubungan antara pola asuh orang tua authoritarian dengan konsep diri siswa kelas XII SMA Kristen 1 Salatiga. Dalam penelitian ini yang menjadi populasi adalah siswa kelas XII SMA Kristen 1 Salatiga yang berjumlah 199 orang.

Dalam penelitian ini teknik pengambilan sampel yang digunakan adalah purposive sampling yaitu penentuan sampel dengan pertimbangan tertentu. Sampel dalam penelitian ini adalah siswa kelas XII yang mengalami pola asuh orang tua otoriter dengan 
jumlah 64 orang siswa, yang dapat dilihat dari hasil sebaran instrument pola asuh orang tua yang sudah dilakukan.

Teknik pengumpulan data yang digunakan yaitu skala dan kuesioner. Skala yang digunakan untuk mengetahui pola asuh otoriter siswa adalah Scale Of Parenting yang disusun oleh Kurukkan dan Gafoor (2014). Sedangkan kuesioner yang digunakan untuk mengukur konsep diri siswa adalah Self-Description Questionnaire II (SDQ-II) yang disusun oleh Herbert W. Marsh (1990).

Teknik pengolahan data yang dipergunakan adalah dengan perhitungan komputasi program SPSS (Statistical Package for Social Sience) yaitu program computer yang mampu memproses data statistik secara tepat dan cepat. Sementara teknik analisis korelasi yang digunakan dalam penelitian ini adalah menggunakan analiisis Pearson korelasi product moment dengan taraf signifikansi sebesar $0,05(\alpha=0,05)$. Dalam penelitian ini menggunakan dua variable, yaitu pola asuh orang tua authoritarian $(X)$ sebagai variable independen dengan konsep diri (Y) sebagai variable dependent.

\section{HASIL DAN PEMBAHASAN}

Pola asuh orang tua dibagi menjadi empat tipe pola asuh yaitu otoriter, authoritatif (demokratis), indulgent, dan negligent. Pada penelitian ini diperoleh data pola asuh orang tua menurut persepsi siswa kelas XII SMA Kristen 1 Salatiga (Tabel 2). Terdapat 64 $(32.16 \%)$ siswa yang mengalami tipe pola asuh otoriter, sehingga selanjutnya dicari hubungan pola asuh orang tua otoriter dengan konsep diri siswa (Tabel 3), dimana terdapat $32(50 \%)$ siswa yang yang memiliki konsep diri dalam kategori tinggi.

Tabel 2. Pola Asuh Orang tua Siswa kelas XII SMA Kristen 1 Salatiga

\begin{tabular}{lrr}
\hline Pola Asuh & Jumlah & Persentase \\
\hline Authoritarian (otoriter) & 64 & $32.16 \%$ \\
\hline Authoritative (demokratis) & 35 & $17.58 \%$ \\
\hline Indulgent & 61 & $30.65 \%$ \\
\hline Negligent & 39 & $19.59 \%$ \\
\hline Total & 199 & $100 \%$ \\
\hline
\end{tabular}

Tabel 3. Kategori Konsep Diri siswa kelas XII SMA Kristen 1 Salatiga

\begin{tabular}{lllrr}
\hline No & Kategori & Range skor & Frek & $\%$ \\
\hline 1 & Sangat Rendah & $102-162$ & 0 & 0 \\
\hline 2 & Rendah & $163-223$ & 1 & 1.56 \\
\hline 3 & Sedang & $224-284$ & 30 & 46.87 \\
\hline 4 & Tinggi & $285-345$ & 32 & 50 \\
\hline 5 & Sangat Tinggi & $346-407$ & 1 & 1.56 \\
\hline Jumlah & & 64 & 100 \\
\hline
\end{tabular}


Sebelum melakukan pengujian korelasional dengan Pearson Product Moment, terlebih dahulu dilakukan uji asumsi normalitas agar nantinya dapat menentukan pilihan analisis korelasi yang parametik atau non parametik. Pengujian terhadap normalitas sebaran data variabel penelitian menggunakan One Sample-Kolmogrov-Smirnov Test.

Hasil penelitian munujukkan tampak bahwa untuk variabel pola asuh authoritarian (otoriter) diperoleh nilai Kolmogorov-Smirnov Z sebesar 0,638 dengan koefisien Asymp.Sig sebesar 0,811 >0,05, sehingga dapat dinyatakan bahwa sebaran data variabel pola asuh orang tua otoriter berdistribusi normal. Untuk variabel konsep diri diperoleh nilai Kolmogorov-Smirnov $Z$ sebesar 0,597 dengan koefisien Asymp.Sig sebesar 0,868 > 0,05, sehingga dapat dinyatakan bahwa variabel konsep diri mempunyai sebaran distribusi normal.

Koefisien korelasi Product Moment variabel pola asuh otoriter dengan variabel konsep diri siswa $\mathrm{r}_{\mathrm{xy}}=0,110$ dengan $\mathrm{P}=0,388>0,05$. Dari hasil uji korelasi dapat disimpulkan bahwa tidak ada hubungan yang signifikan antara pola asuh orang tua otoriter dengan variabel konsep diri siswa Kelas XII SMA Kristen 1 Salatiga. Yang artinya, kenaikan ataupun penurunan skor variabel pola asuh otoriter dan skor variabel konsep diri tidak dapat ditentukan. Karena variabel pola asuh otoriter tidak terdapat hubungan yang signifikan dengan variabel konsep diri, maka perlu dilakukan analisis lebih mendalam untuk setiap aspek pola asuh otoriter yaitu tuntutan dan responsif dengan konsep diri.

Hasil analisis korelasi aspek tuntutan orang tua otoriter dengan konsep diri siswa menunjukkan bahwa tidak ada hubungan yang sinifikan antara aspek tuntutan orang tua dengan konsep diri, dengan koefisien korelasi Product Moment sebesar 0.090 dengan $\mathrm{P}=$ $0.481>0,05$. Yang artinya, kenaikan ataupun penurunan skor aspek tuntutan orang tua dan skor variabel konsep diri tidak dapat ditentukan.

Perhitungan korelasi aspek responsif dengan konsep diri menunjukkan bahwa tidak ada hubungan yang signifikan antara aspek responsif orang tua dengan variabel konsep diri dengan koefisien korelasi Product Moment antara aspek responsif orang tua dengan konsep diri siswa sebesar 0,050 dengan $\mathrm{P}=0,695>0,05$. Yang artinya, kenaikan ataupun penurunan skor aspek responsif orang tua dan skor variabel konsep diri tidak dapat ditentukan.

Hipotesis yang diajukan dalam penelitian ini ada hubungan yang signifikan antara pola asuh orang tua otoriter dengan konsep diri siswa kelas XII SMA Kristen 1 Salatiga. Namun, analisis korelasi menunjukkan bahwa tidak ada hubungan yang signifikan antara pola asuh orang tua otoriter dengan konsep diri siswa kelas XII SMA Kristen 1 Salatiga sehingga hipotesis yang diajukan ditolak.

Berdasarkan hasil analisis menunjukkan korelasi Product Moment sebesar $\mathrm{r}_{\mathrm{xy}}=0,110$ dengan $\mathrm{P}=0,388>0,05$ sehingga diketahui tidak ada hubungan yang signifikan antara variabel pola asuh orang tua otoriter dengan variabel konsep diri siswa kelas XII SMA Kristen 1 Salatiga. Artinya kenaikan ataupun penurunan skor variabel pola asuh otoriter dan skor variabel konsep diri tidak dapat ditentukan.

Sesuai dengan teori Marsh (1990) konsep diri siswa tidak hanya berhubungan dengan aspek hubungan dengan orang tua namun, konsep diri memiliki hubungan 
dengan aspek-aspek lain seperti evaluasi diri yang terbentuk melalui pengalaman yang disertai interpretasi terhadap lingkungan sekolah, seperti minat, kemampuan dan ketertarikan terhadap mata pelajaran sekolah. Konsep diri juga berhubungan dengan penampilan fisik, kejujuran-kepercayaan, kemampuan fisik, stabilitas emosi, hubungan dengan teman sejenis kelamin, hubungan dengan teman lawan jenis, dan kepercayaan terhadap diri sendiri serta kepuasaan terhadap dirinya sendiri.

Hasil penelitian ini sejalan dengan hasil penelitian Rama (2014) yang berjudul "hubungan pola asuh orang tua authoritarian dengan konsep diri siswa kelas XII SMA Kristen Payeti di Sumba timur". Hasil penelitian diketahui tidak ada hubungan yang signifikan antara pola asuh orang tua authoritarian dengan konsep diri siswa. Adanya kesamaan hasil penelitian yang dilakukan, teori pola asuh authoritarian yang digunakan dalam penelitian ini sama-sama menggunakan teori Baumrind (1991).

Hasil penelitian ini sejalan dengan hasil penelitian Kamilah (2005) hasil penelitian diketahui tidak ada hubungan yang signifikan antara pola asuh orang tua authoritarian dengan konsep diri. Adanya kesamaan hasil penelitian yang dilakukan, teori pola asuh authoritarian yang digunakan dalam penelitian ini sama menggunakan teori Baumrind (1991). Menurut Margono (2009), adanya kesamaan hasil penelitian dipengaruhi oleh teori yang digunakan

Hasil penelitian ini bertentangan dengan hasil pra penelitian yang sudah dilakukan sebelumnya pada 30 siswa kelas XII SMA Kristen 1 Salatiga. Adanya perberdaan hasil penelitian dengan pra penelitian dikearenakan jumlah responden yang berbeda. Menurut Margono (2009) terbuktinya hasil penelitian juga dipengaruhi oleh jumlah responden.

Hasil penelitian ini juga tidak sejalan dengan penelitian Rahman, Shahrin, dan Kamaruzaman (2017) yang menjelaskan bahwa orang tua dengan pola asuh otoriter menghasilkan konsep diri anak yang rendah dimana anak cenderung merasa gagal dalam hidup mereka karena selalu membuat masalah dan merasa tidak puas dalam segala hal tentang diri mereka sendiri atau hal-hal lain yang terjdai di sekitar mereka. Adanya perbedaan hasil penelitian, teori dan alat ukur konsep diri yang digunakan dalam kedua penelitian ini berbeda. Dalam penelitian sebelumnya kuesioner konsep diri yang digunakan adalah Tennessee Self-Concept yang dibuat oleh Fitz dan Warrant (1996). Perbedaan alat ukur yang digunakan juga mempengaruhi hasil hipotesis yang diperoleh dalam sebuah penelitian (Margono, 2009).

\section{SIMPULAN}

Hasil penelitian ini menemukan bahwa tidak ada hubungan yang signifikan antara pola asuh orang tua otoriter dengan konsep diri siswa kelas XII SMA Kristen 1 Salatiga. Artinya, kenaikan ataupun penurunan skor variabel pola asuh otoriter dan skor variabel konsep diri tidak dapat ditentukan.

Dalam mengembangkan konsep diri siswa, sekolah tidak perlu menghubungkan dengan pola asuh otoriter karena hasil penelitian menunjukkan tidak ada hubungan yang signifikan antara pola asuh orang tua otoriter dengan konsep diri siswa. Konsep diri siswa dapat dipengaruhi oleh evaluasi diri siswa yang terbentuk melalui pengalaman siswa 
yang disertai dengan interpretasi terhadap lingkungan sekolah seperti minat, kemampuan dan ketertarikan siswa terhadap mata pelajaran sekolah (Marsh, 1990).

Hasil penelitian ini menunjukkan tidak ada hubungan yang signifikan antara pola asuh orang tua otoriter dengan konsep diri siswa. Bagi peneliti selanjutnya diharapkan dapat memperhatikan variabel lain seperti salah satu faktor-faktor tugas perkembangan remaja yaitu menerima perubahan fisik. Faktor tersebut memiliki hubungan dengan konsep diri remaja. Dimana, remaja secara sadar mengamati dan merasakan adanya perubahan dalam penampilan fisiknya, remaja memiliki penilaian terhadap apa yang dipersepsikannya terhadap perubahan fisik pada dirinya mempengaruhi terbentuknya konsep diri remaja.

\section{REFERENSI}

Baumrind, D. (1966). Effects of authoritative parental control on child behavior. Child Development, 37(4), 887-907.

Baumrind, D. (1991). The influence of parenting style on adolescent competence and substance use. The Journal of Early Adolescence, 11(1), 56-95.

Chaplin, C. P. (1989). Kamus lengkap psikologi. Jakarta: Rajawali Pers.

Gafoor, A \& Kurukkan, A. 2014 Construction and Validation of Scale of Parenting Style. Guru Jurnal of Behavioral and Social Sciences, 2(4), 315-323.

Ganda. (2015). Hubungan antara pola asuh orang tua dengan konsep diri siswa kelas XI SMA Kristen 1 Salatiga (Skripsi Universitas Kristen Satya Wacana).

Kamilah. N. (2005). The relationship between self-concept, motivation and parenting style and achievement. (Bachelor's Degree Thesis of University Teknologi Malaysia).

Margono. (2009). Metodologi penelitian pendidikan. Jakarta: Rineka Cipta.

Marsh, H. W. (1990). Self-description questionnaire II (SDQ-II) Manual. Sydney: Western Sydney University.

Marsh, H. W., \& Craven, R. (1996). Academic self-concept: Beyond the dustbowl. In Handbook of classroom assessment (pp. 131-198). Cambridge, MA: Academic Press.

Rahman, O. A., Shahrin, N. N., \& Kamaruzaman, Z. (2017). The relationship between parenting style and self-concept. Jurnal of Education and Social Science, 7(1), 190-194.

Rama, O. N. (2014). Hubungan antara kecenderungan pola asuh authoritarian orang tua dengan konsep diri pada remaja kelas XII SMA Kristen Payeti di Sumba Timur (Skripsi Universitas Kristen Satya Wacana). 
INDONESIAN JOURNAL OF EDUCATIONAL COUNSELING 2019, 3(1), 51-60

Sugiyono. (2015). Metode penelitian kuantitatif, kualitatif dan kombinasi (Mixed methods). Bandung: Alfabeta.

Vinayastri, A. (2015). Pengaruh pola asuh (parenting) orang-tua terhadap perkembangan otak anak usia dini. Jurnal Ilmiah WIDYA, 1(1), 33-42. 